\title{
Circulating tumor cells in precision oncology: clinical applications in liquid biopsy and 3D organoid model
}

\author{
Chang Yang ${ }^{1+}$, Bai-Rong Xia ${ }^{1+}$, Wei-Lin Jin ${ }^{2,3^{*}}$ and Ge Lou ${ }^{1 *}$ (D)
}

\begin{abstract}
Circulating tumor cells (CTCS) are a rare subset of cells found in the blood of patients with solid tumors, which function as a seed for metastases. Cancer cells metastasize through the bloodstream either as single migratory CTCs or as multicellular groupings-CTC clusters. The CTCs preserve primary tumor heterogeneity and mimic tumor properties, and may be considered as clinical biomarker, preclinical model, and therapeutic target. The potential clinical application of CTCs is being a component of liquid biopsy. CTCs are also good candidates for generating preclinical models, especially 3D organoid cultures, which could be applied in drug screening, disease modeling, genome editing, tumor immunity, and organoid biobanks. In this review, we summarize current knowledge on the value and promise of evolving CTC technologies and highlight cutting-edge research on CTCs in liquid biopsy, tumor metastasis, and organoid preclinical models. The study of CTCs offers broad pathways to develop new biomarkers for tumor patient diagnosis, prognosis, and response to therapy, as well as translational models accelerating oncologic drug development.
\end{abstract}

Keywords: Circulating tumor cells, Liquid biopsy, Precision oncology, Tumor metastasis, 3D organoid model

\section{Introduction}

Although cancer incidence rate is stable in women and declining by approximately $2 \%$ per year in men, and cancer death rate in women and men declined annually by $1.4 \%$ and $1.8 \%$, respectively, over the past decade [1], cancer remains the second leading cause of death globally and is responsible for an estimated 9.6 million deaths in 2018. Globally, approximately 1 in 6 deaths are due to

\footnotetext{
*Correspondence: weilinjin@yahoo.com; weilinjin@sjtu.edu.cn; louge_ cherry@163.com

${ }^{\dagger}$ Chang Yang and Bai-Rong Xia contributed equally to this work ${ }^{1}$ Department of Gynecology Oncology, The Tumor Hospital, Harbin Medical University, Harbin 150086, People's Republic of China

${ }^{2}$ Institute of Nano Biomedicine and Engineering, Shanghai Engineering Center for Intelligent Diagnosis and Treatment Instrument, Department of Instrument Science and Engineering, Key Laboratory for Thin Film and Microfabrication Technology of Ministry of Education, School of Electronic Information and Electronic Engineering, Shanghai Jiao Tong University, Shanghai 200240, People's Republic of China

Full list of author information is available at the end of the article
}

cancer [2]. Limitations on the knowledge about cancer lead to high mortality. We routinely treat cancer patients with surgery, chemotherapy, and radiotherapy, ignoring inter- and intra-patient heterogeneity [3-6]. To address this issue, precision oncology is indispensable. Liquid biopsy [7], also known as fluid biopsy or fluid phase biopsy has potential in analyzing the genomic landscape of patients with cancer, supervising treatment responses, monitoring minimal residual disease, and managing noninvasive therapy resistance. Compared with traditional tissue biopsy, liquid biopsy is noninvasive and real-time. Blood samples are the most common materials for analysis, which contain cell-free DNA (cfDNA) [8]; cell-free tumor DNA (ctDNA) [9]; vesicles(such as exosomes [10]) tumor-educated blood platelets (TEPs) [11] and circulating tumor cells (CTCs) (Fig. 1a). Other body fluids such as cerebrospinal fluid (CSF) [12]; saliva [13]; pleural effusions [14]; urine [15] and stool [16] have shown captivity for diagnoses. CTCs play a vital role in precision

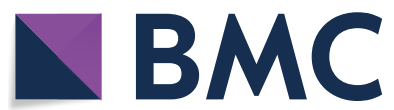

(c) The Author(s) 2019. This article is licensed under a Creative Commons Attribution 4.0 International License, which permits use, sharing, adaptation, distribution and reproduction in any medium or format, as long as you give appropriate credit to the original author(s) and the source, provide a link to the Creative Commons licence, and indicate if changes were made. The images or other third party material in this article are included in the article's Creative Commons licence, unless indicated otherwise in a credit line to the material. If material is not included in the article's Creative Commons licence and your intended use is not permitted by statutory regulation or exceeds the permitted use, you will need to obtain permission directly from the copyright holder. To view a copy of this licence, visit http://creativeco mmons.org/licenses/by/4.0/. The Creative Commons Public Domain Dedication waiver (http://creativecommons.org/publicdomain/ zero/1.0/) applies to the data made available in this article, unless otherwise stated in a credit line to the data. 


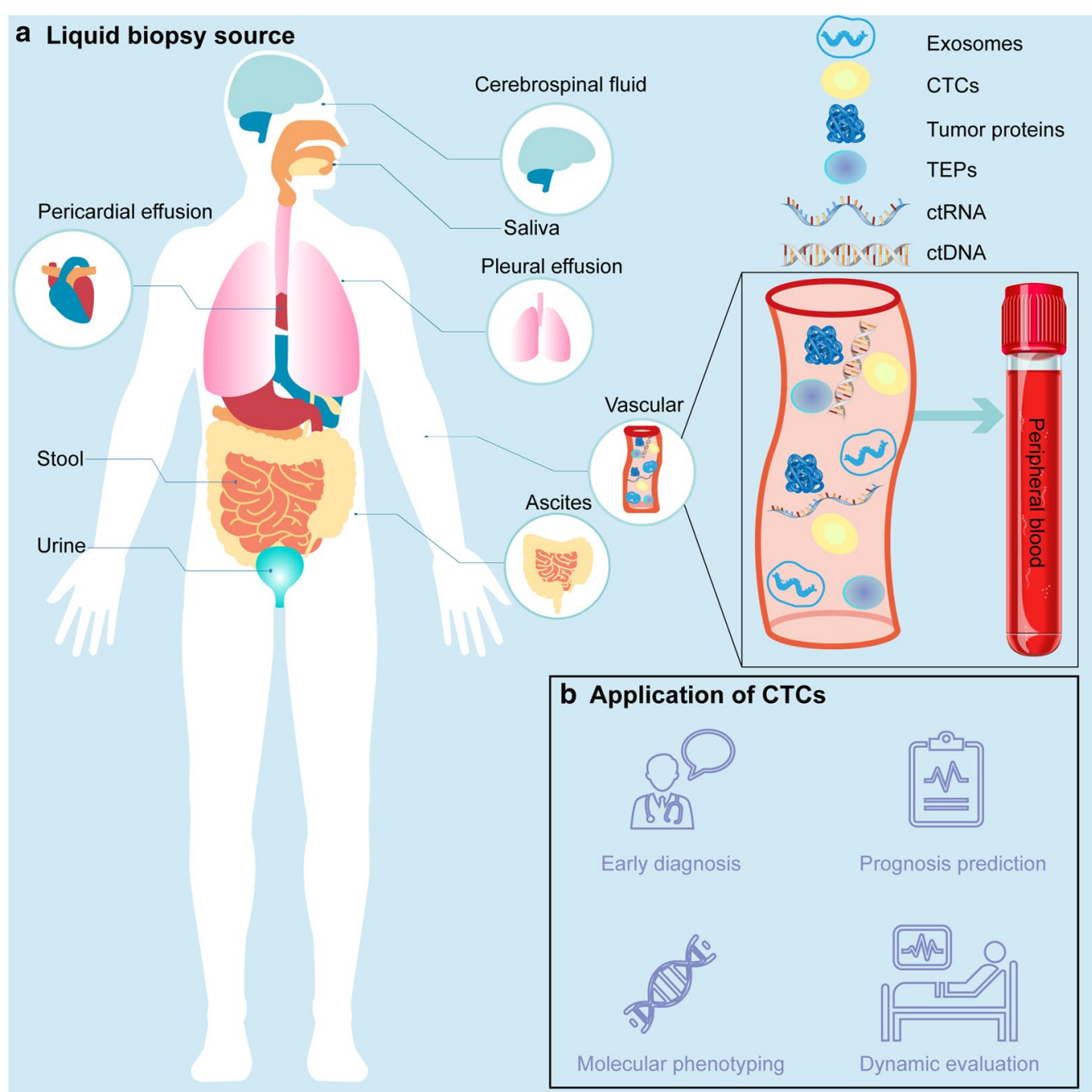

Fig. 1 Basic introduction of the liquid biopsy approaches and applications of CTCs as liquid biopsy. a Liquid biopsy approaches involve peripheral blood, precardial effusion, stool, urine, ascites, pleural effusion, saliva and cerebrospinal fluid. Moreover, peripheral blood biopsy include isolation of circulating tumor cells(CTCs), circulating tumor DNA (ctDNA), circulating tumor RNA(ctRNA) and exosomes. b Applications of CTCs as liquid biopsy in early diagnosis, prognosis prediction, and disease monitoring, molecular phenotyping, therapy response evaluation

oncology (Fig. 1b) due to its characteristics of non-invasion, real-time capability, and molecular heterogeneity.

As a seed for metastases, CTCs conserve tumor heterogeneity and mimic tumor properties, allowing them to be applied to therapeutic targets and clinical biomarkers for disease screening, dynamic monitoring, and prognosis prediction. Moreover, a CTC-derived 3D organoid model can be applied to screening tests of drug sensitivity [17] and analysis of multiplexed proteomic of CTCs [18]. Thus, although limitations exist, development of CTC isolation and culture are necessary for therapy, disease evolution, and real-time genomic characterization. In this review, we focus on the clinical applications of CTCs, especially in liquid biopsy and 3D organoid model.

\section{Technologies for CTC isolation and identification}

Circulating tumor cells (CTCs) with morphologic features similar to the primary solid tumor were initially discovered by Thomas Ashworth [19] through an autopsy of a cancer patient 150 years ago. A number of scientists have demonstrated that CTCs can be used as a predictor of clinical prognosis and treatment efficacy evaluation [20-23]. At first, scientists used the CellSearch system, which was the only device for CTC analysis approved by the United States Food and Drug Administration (FDA), to enrich and enumerate CTCs from peripheral 
blood. Finally, researchers discovered that the enumeration of CTCs is insufficient because variable phenotypes of CTCs in circulation have different potentials in tumor progress. Detailed developments [19, 24-30] in the history of CTCs are shown in Fig. 2.

Abnormal proliferation and metabolism of tumor cells, disorder and changes in the composition of cells, unnatural gene expression and modification, and synthesis and accumulation of polar particulate lead to changes in the physical and biological properties of CTCs. Scientists have developed technologies for enrichment, isolation, and identification of CTCs according to these physical and biological changes. The methods of technologies for CTC isolation from the review by Rubis [31], are referenced, but only the latest technologies are listed in Table 1 . Methods to isolate CTCs developed rapidly with the emergence of the microfluidic chip system and nanotechnologies. Using engineered mouse models in cancer research, Hamza et al. [32] have solved the problem of having small total blood volume and rare CTCs using an optofluidic-based approach, eliminating confounding biases induced by inter-mouse heterogeneity. Antfolk et al. [33] have isolated breast cancer cells (MCF7) from peripheral blood with an efficiency of $91.8 \pm 1.0 \%$ based

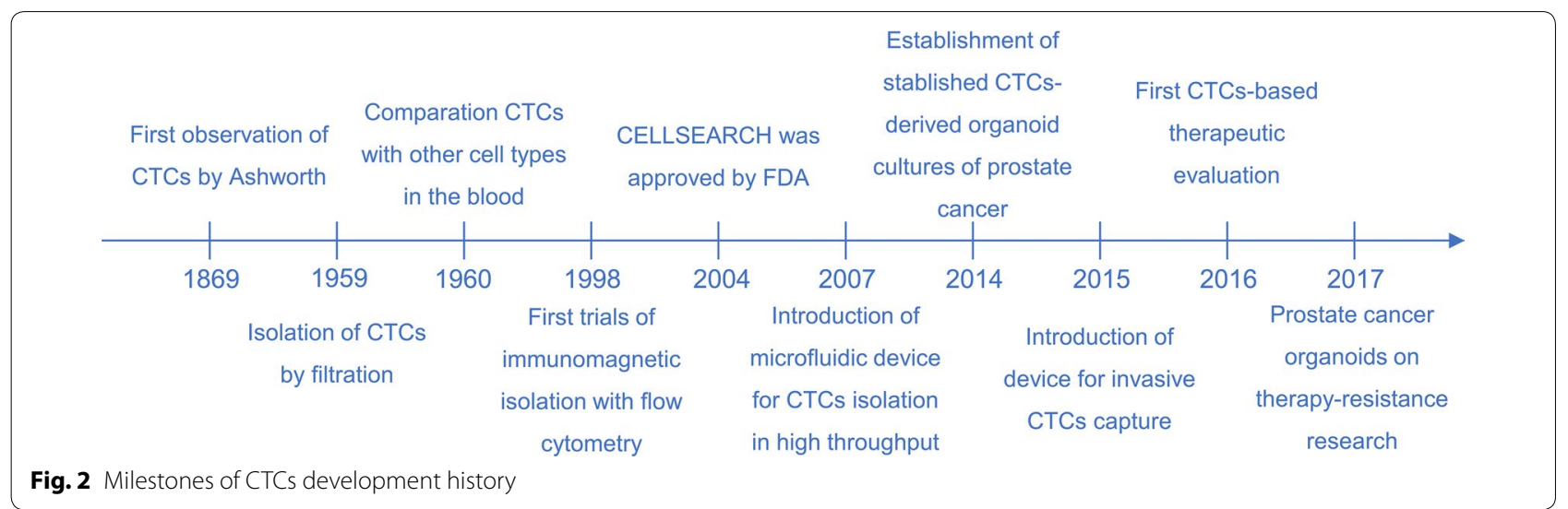

Table 1 CTCs isolation, enrichment, and identification technologies

\begin{tabular}{|c|c|c|c|}
\hline Category & Strategy & Technology/device & Refs \\
\hline \multirow[t]{7}{*}{ Biological properties } & Surface marker detection & Ferrofluids coated to EpCAM/CellSearch ${ }^{\circledR}$ & {$[81]$} \\
\hline & & Magnetic beads coated to EpCAM + MUC1/AdnaTest ${ }^{\circledR}$ & {$[111]$} \\
\hline & & EpCAM-coated wire for in vivo isolation/CellCollector ${ }^{\mathrm{Tм}}$ & {$[112,113]$} \\
\hline & & CD45+ depletion & {$[114]$} \\
\hline & Surface marker detection combined microfluid & Microposts or channels coated to EpCAM/CTC-Chip/HB-Chip & {$[25,102]$} \\
\hline & & FICOLL and EpCAM-based microfluidic device/Isoflux ${ }^{\circledR}$ & {$[115]$} \\
\hline & & Glycan-affinity microfluidic devices & {$[35]$} \\
\hline \multirow[t]{10}{*}{ Physical properties } & Size-based enrichment & $\mathrm{ISET}^{\circledR}$ & {$[116]$} \\
\hline & Density-based & OncoQuick ${ }^{\circledR}$ & {$[117]$} \\
\hline & Centrifugal force-based & cascaded microfluidic device & {$[34]$} \\
\hline & Acoustophoresis-based & Acoustofluidic & {$[33]$} \\
\hline & Nanorough polystyrene substrates adherence-based & Nanostructured polystyrene well plates & {$[118]$} \\
\hline & Deformability-based & JETTATM & {$[119]$} \\
\hline & Optofluidic-based & Optofluidic real-time cell sorter & {$[32]$} \\
\hline & Dielectric-based & DEP & {$[120]$} \\
\hline & & DEP-LFFF & {$[121]$} \\
\hline & & DEP Array & {$[122]$} \\
\hline \multirow[t]{3}{*}{ Functional assays } & Invasive capacity & VitaAssay $^{\text {TM }}$ & {$[123]$} \\
\hline & Protein release during culture & EPISPOT assay & {$[124]$} \\
\hline & Telomerase expression & TelomeScan $^{\circledR}$ & {$[125]$} \\
\hline
\end{tabular}


on an integrated acoustophoresis-based rare-cell enrichment system combined with integrated concentration. Abdulla et al. [34] have introduced a cascaded microfluidic device that can separate $80.75 \%$ of human lung cancer cells (A549) and 73.75\% of human breast cancer cells (MCF-7) from the human whole-blood system based on their physical properties within 20 min with a cell viability of $95 \%$ and $98 \%$, respectively. Neves et al. [35] have constructed a glycan affinity-based microfluidic device for selective isolation of membrane protein O-glycan sialyl-Tn antigen $(\mathrm{STn}+)$, which are more sensitive than size-based microchips for CTC detection and are clinically relevant with metastasis in bladder and colorectal tumors. To conclude, technologies for enrichment, isolation, and identification of CTCs according to physical and biological changes both have limitations, such as low purity, low cell viability, and low intermediate throughput. It is urgent to integrate the best of these technologies to generate a new approach that yield high throughput and high purity. With the emergence of numerous technologies and platforms for isolating and further analyzing CTCs, physicians have realized the importance of CTCs as liquid biopsy and therapeutic target.

\section{Clinical application of CTCs}

\section{Circulating tumor cells as a therapeutic target}

As previously mentioned, CTCs are responsible for tumor metastasis. Furthermore, considering that most deaths induced by cancer are due to metastasis [36], a new cancer therapy that considers CTCs as a target is envisioned by scientists. Thus, the disruption of cancer cell dissemination would represent a powerful therapeutic strategy. However, owing to the lack of technical evaluation of the effects of CTC elimination in vivo, most studies assume that removing CTCs could radically prevent tumor metastasis. To address this condition, Kim et al. [37] have transplanted green fluorescent protein (GFP)-expressing CTCs into mice, applied photodynamic therapy to specifically clear GFP-expressing CTCs, appraised the therapeutic efficacy of CTC elimination, and finally demonstrated that elimination of CTCs could prevent metastasis and prolong the survival term of the tumor-bearing mice.

In recent years, Rana et al. [38] have established a selectin-based implantable shunt device based on the molecular mechanisms involved in CTC extravasation. The device is a microtube decorated with E-selectin molecules and tumor necrosis factor-related apoptosis-inducing ligand (TRAIL) in its surface to guide CTC rolling and the eventual tumor cell apoptosis. The application of TRAIL therapy into solid tumors is restrictive on account of TRAIL resistance. Phipps et al. [39] demonstrated that after separation from the extracellular matrix, TRAILresistant cancer cells became more sensitive. Furthermore, in the study by Mitchell [40], tumor cells showed enhanced sensitivity to TRAIL when exposed to fluid shear stress.

To conclude, CTCs, as a seed for metastasis, could be an effective therapeutic target toward limiting its recirculation in the blood, slowing its expansion to secondary lesions, and relieving overall tumor burden in cancer patients after the resection, radiation, or chemotherapy of a primary neoplasia. With an extensive study of the dynamics and mechanisms of CTC recirculation, a new therapeutic method tailored to oppose tumor seeding for advanced tumor patients is promising $[31,41]$.

\section{Circulating tumor cells in liquid biopsy Prognosis prediction}

The detection of CTCs should focus on identifying subpopulations of CTCs resulting in tumor metastasis because of the heterogeneous properties of CTCs [28,

Table 2 Summary of studies on CTCs in precision medicine

\begin{tabular}{|c|c|c|c|}
\hline Category & Proposed functions & Representative genes & Refs \\
\hline \multirow[t]{4}{*}{ Oncogene validation } & Epithelial mesenchymal transition (EMT) & TGFß1, SNAIL1 & {$[126,127]$} \\
\hline & Metastasis & FABP, CEACAM5 & [128] \\
\hline & Stem cell phenotype & CD24, CD44, CD133, ALDH1 & [127] \\
\hline & Cell proliferation & RRM1, MAPK14 & [126] \\
\hline \multirow[t]{2}{*}{ Targeted therapy } & Changing biomarker & HER2, EGFR & {$[129,130]$} \\
\hline & Signaling pathway & AKT1, AKT2, PIK3R1, PTEN & [131] \\
\hline \multirow[t]{5}{*}{ Drug screening } & Biomarkers of therapeutic resistance & RAS, BRAF (colorectal cancer) & [132] \\
\hline & & AR (prostate cancer) & {$[30]$} \\
\hline & Biomarkers of drug sensitivity & ER (endocrine therapy) & [133] \\
\hline & & ERCC1 (chemotherapy) & [134] \\
\hline & & PD1 (immune therapy) & {$[48]$} \\
\hline
\end{tabular}


42]. Moreover, learning the molecular and biological features of CTCs can guide clinical decision-making. Miyamoto et al. [43] have used microfluidic cell enrichment followed by digital quantitation of prostate-derived transcripts to predict metastasis and prognoses; they suggested that monitoring CTC-specific transcripts using this technology can guide clinical therapeutic selection in both malignant and regional prostate cancer. A secondary analysis of a randomized clinical trial has shown that the positive CTC assay of patients suffering from hormone receptor-positive breast cancer provided independent prognostic outcomes for late clinical recurrence, thereby indicating that CTCs may be used to predict late recurrence and guide therapy [44]. Importantly, a further step for the clinical application of CTCs in other carcinomas requires extensive validation.

\section{Early diagnosis}

Several lines of evidence suggest a crucial role of CTCs as a seed for metastases; thus, available data suggest CTCs as a biomarker for early diagnosis. Fan et al. [45] have designed a CTC panel to investigate the clinical value of circulating tumor cells for diagnosis in hepatitis B virusrelated hepatocellular carcinoma. The panel showed prominent performance in early diagnosis and differential diagnosis from liver cirrhosis, chronic hepatitis $B$ infection, and benign hepatic lesion. The area under the curve (AUC) of the CTC panel was 0.88 in training set and 0.93 in validation set. Recently, Zhou et al. [46] have demonstrated that folate receptor positive circulating tumor cells (FR+-CTCs), in combination with maximum tumor diameter (MTD), are reliable methods for determining whether small-sized solitary pulmonary nodules (SPNs) are invasive tumor or not. To conclude, CTCs may have promising beneficial effects in early diagnosis of tumor and may be relevant from the aspect of metastasis prevention.

\section{Molecular phenotyping}

PD-L1 antibody is an emerging anti-tumor regimen with less toxicity and long-term effects for a number of cancers such as non-small-cell lung cancer [47]. Mazel et al. [48] have demonstrated that the expression of PD-L1 highly increased on CTCs obtained from patients with hormone receptor-positive, HER2-negative breast cancer. CTC/PD-L1 analysis might be applied to patients with immune checkpoint blockade as immunoscores because PD-L1 expression categorizes different subsets of CTCs [49].

\section{Dynamic evaluation}

CTCs could be an independent indicator for evaluating tumor invasiveness and guiding clinical treatment because recurrence and metastases are hallmarks of cancer. Scher et al. [50] have used CTCs for therapy response evaluation in patients undergoing castrationresistant prostate cancer. The patients were randomly divided into abiraterone acetate plus prednisone and prednisone-alone groups. Moreover, the biomarkers were measured at baseline and at 4, 8, and 12 weeks. Results proved that CTC enumerations can be used for real-time therapy evaluation. Further trials are ongoing to validate the findings. Li et al. [51] have identified that the CTC levels after therapy may be used to evaluate therapeutic response and predict poor prognosis in advanced gastric cancer (AGC). They enumerated the newly diagnosed AGC patients' CTCs as baseline and evaluated the first response after treatment by CellSearch in 136 patients. Moreover, they have chosen 15 appropriate patients and enumerated the CTCs during the entire treatment for a longitudinal study. In 2019, Balakrishnan et al. [52] have found that chemotherapy induced CTC cluster formation in blood samples indicate disease progression and shorter overall survival. To conclude, these studies may lead to a better understanding of the clinical application for CTCs on dynamic evaluation. To conclude, these studies may improve our understanding of the clinical application of CTCs in dynamic evaluation.

\section{CTC-derived 3D organoid model}

CTC-derived pre-clinical model consists of 2D cultures, spheroid generation, 3D organoid generation, and CTCderived explant (CDX) model, which is an in vivo model compared with other mentioned models. The previous work of our group [53] have summarized that the 3D organoid model has advantages of stable morphology, gene expression and cell signaling, equal behavior and heterogeneity with cancer cells in the tumor mass, high-throughput for drug screening, low cost, and easy operation "in a dish" [54-58]. Moreover, organoids could mimic cancer hypoxia microenvironment. Thus, in this review, applications of organoid technologies in precision medicine are discussed in detail (Fig. 3).

\section{Development of CTC-derived 3D organoid model}

Organoids are miniscule models of tissues that grow in a 3D semisolid extracellular matrix medium with specific growth factor supplied $[59,60]$. In the 1980s, Bissell et al. [61] developed 3D cultures and illustrated how extracellular matrix (ECM) affects gene expression in the breast. In 1990, her group further found that various ECMs play an important role in maintaining the morphology and function of murine mammary cells [62]. In 2007, Bissell et al. [63] proposed two procedures for 3D culture of normal and malignant human mammary cells. Formation of an organoid with single epithelial cells needs 7-10 days 


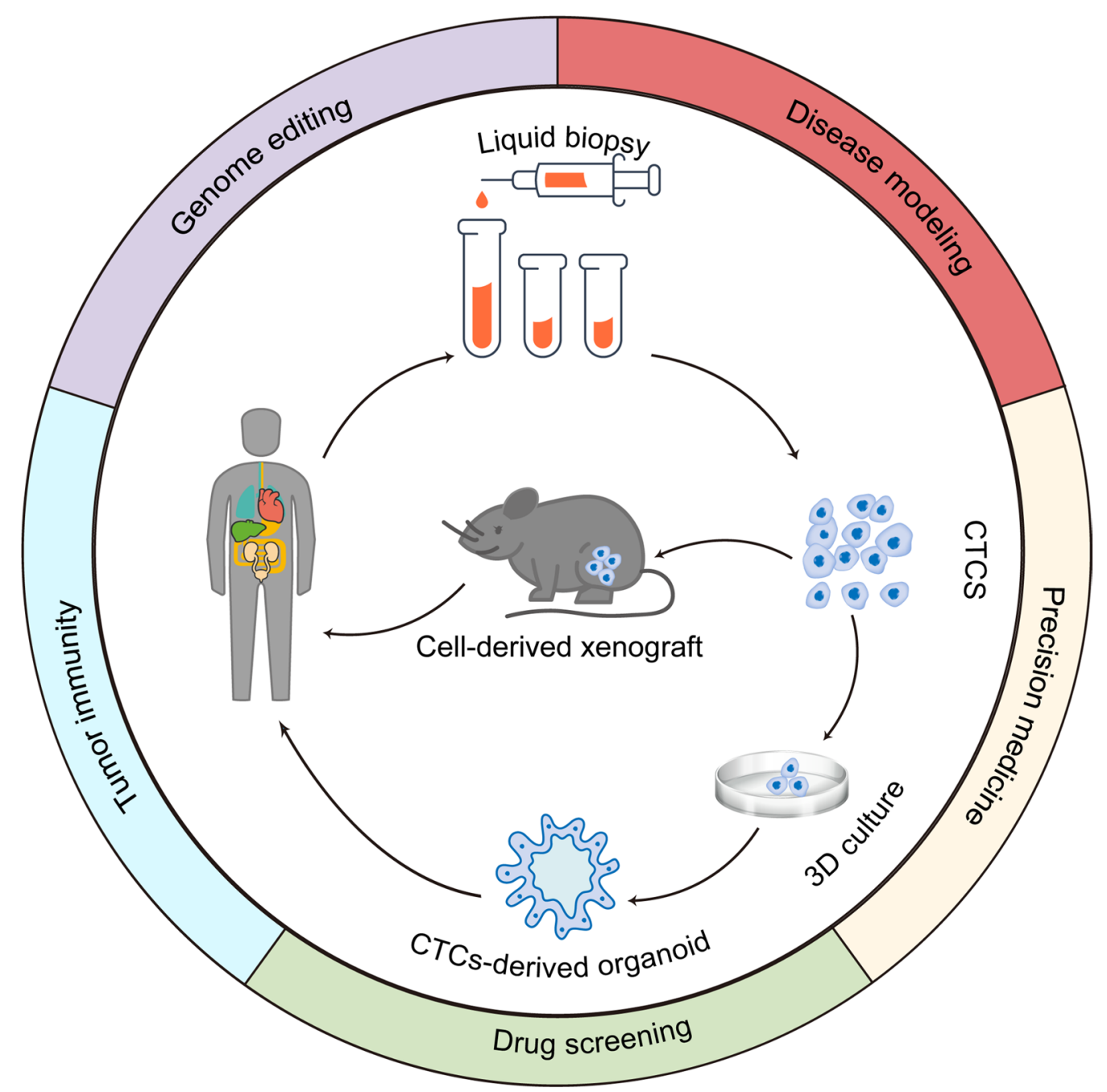

Fig. 3 Basic introdction of CTCs-derived organoid in precision medcine

and the formed organoid can be separated into single cells to initiate a new organoid. This long-term organoid culture technology was first developed by Sato et al. [59], who cultured mouse small intestinal crypts in stable media condition for growth and finally established the mini-gut culture system. Subsequently, this technology was widely used in other organs including colon, lung, prostate, stomach, liver, pancreas, and breast for molecular research and drug screening [60, 64-68].

As CTCs are rare in blood, establish of CTCs-derived 3D organoid model are late. Zhang et al. [69] isolated CTCs from the peripheral blood of patients with breast cancer, cultured them in vitro, and finally developed CTCs lines. Moreover, they found that CTC lines maintained the characteristic of brain metastatic breast cancer (BMBC) were seriously invasive and metastatic. In 2014, Zhang et al. [70] have successfully designed a three-dimensional (3D) co-culture model for better isolating and culturing CTCs. After capturing CTCs from patients' blood sample through a CTC-capture chip, they introduced fibroblasts and extracellular matrix $(E C M)$ to the same chip to establish a co-culture environment, which could simulate a tumor microenvironment to support tumor development. Furthermore, it has been confirmed that CTCs in 3D co-culture model had matched mutation with the primary cancer, which could be applied into clinical application for evaluation of disease progress. Collectively, with the isolation and culture technology for CTCs evolution, CTCs-derived 3D organoids model will be widely used in clinical.

\section{Potential application of CTC-derived 3D organoids}

Disease modeling Cancer progression is a multi-step accumulation process, such as angiogenesis, metastasis, 
and drug resistance, leading to difficulties in screening pathogenic gene events with specific stages in carcinogenesis. Organoids have a potential to model cancer and identify driver genes due to the convenient manipulation of retroviruses, inhibitors, and CRISPR/Cas9 approaches [58, 68, 71]. In 2015, Drost et al. demonstrated that organoids with triple mutations $\left(\mathrm{APC}^{\mathrm{KO}}, \mathrm{TP}^{\mathrm{KO}}{ }^{\mathrm{KO}}\right.$, and $\mathrm{KRAS}^{\mathrm{G} 12 \mathrm{D}}$ ) showed slower growth than those with quadruple mutations $\left(\mathrm{APC}^{\mathrm{KO}}, \mathrm{TP} 53^{\mathrm{KO}}, \mathrm{KRASG}^{12 \mathrm{D}}\right.$, and $\mathrm{SMAD} 4^{\mathrm{KO}}$ ) within immuno-deficient mice injected with intestinal organoid model [58]. In 2017, Fumagalli et al., using the same model, proved that the subsequent mutation of oncogenes $\left(\mathrm{APC}^{\mathrm{KO}}, \mathrm{TP}_{5} 3^{\mathrm{KO}}, \mathrm{KRAS}^{\mathrm{G} 12 \mathrm{D}}\right.$, and SMAD4 ${ }^{\mathrm{KO}}$ ) promoted primary tumor growth, migration, and metastasis after orthotopic transplantation of organoids [71]. As CTCs could be obtained using a noninvasive method, it is easy to build a biobank for patients. Thus, in establishing biobanks of multiple organoid lines in different stages of same patients, CTC-derived organoids can help monitor metastatic progression.

Drug discovery CTC-derived models that contain pathologies of patients are crucial for screening specific drugs. In 2014, Hodgkinson et al. [72] demonstrated that CTCs derived from patients with small-cell lung carcinoma mirrored the patient's response to platinum, and etoposide treatment implied that CTC-derived explants could be applied in supervising the dynamic patterns of a tumor's drug susceptibility and screening new therapeutic targets. In 2016, Boehnke et al. [73] successfully applied patient-derived colorectal cancer (CRC) organoids to high-throughput screening and drug discovery. In 2018, Sachs et al. [64] demonstrated that organoid lines generated from patient samples could be exploited to formulate a standard of care for different breast cancer subtypes. Therefore, various studies significantly showed the immense potential of organoid technology in revealing the molecular basis of drug response.

Precision medicine A new concept in managing treatment programs, precision medicine considers individual differences of genes and environment (Table 2) [74]. In 2015, Van de Wetering et al. [75] reported that porcupine, a small molecule inhibitor of Wnt secretion, was viable only in a patient-derived organoid line with a mutation in the Wnt feedback regulator RNF43, implying the drug sensitivity in a subset of RNF43 mutation CRC patients. In 2017, Zhang et al. [76] proposed that CTC-derived organoid was useful in forecasting the therapeutic response to specific ALK inhibitors (ceritinib and crizotinib). In conclusion, CTC-derived organoids are available for drug screening based on the most recent genetic profiling, thereby settling the problem of drug resistance and invalid treatment.

Genome editing CRISPR/Cas9, a technique that utilizes the mechanism of innate bacterial defense against bacteriophages, has been widely used in various fields of molecular biology since 2012. The indispensable roles of the combination of CRISPR and organoids focusing on the exploration of human tumorigenesis, heterogeneity, and metastasis have been summarized in the previous review [53].

Tumor immunity Recently, cancer immunotherapies, such as CTLA-4 and PD-1/PD-L1, have sparked intense debate and research because of their substantial clinical benefits for advanced cancer patients. Dijkstra et al. [77] have established and confirmed a platform that culture autologous tumor organoids together with peripheral blood lymphocytes to evaluate and stimulate tumor-specific $T$ cell responses to epithelial cancers. They have demonstrated that the value and novelty of this platform is to isolate tumor-reactive $\mathrm{T}$ cells and evaluate the therapeutic effect of T-cell-mediated attacks for the first time. Ultimately, with the improvement in success rate, this platform brings a bright prospect for patients with advanced cancer.

\section{CTCs and tumor metastases}

The motility and invasiveness of tumor cells initiate the onset of metastatic procedure [78], which consists of the steps: cancer cells separate from the primary tumor, seed in the blood circulation, sustain in circulation, extravasate into distant organs, and locate at secondary sites (Fig. 4a). Thus, finding CTCs in circulation indicates metastasis and poor prognoses in cancer patients [79-84]. However, not all CTCs are metastatic, since most of the CTCs in the circulation are degraded due to their half-life. Stott et al. have reported that the number of CTCs of $75 \%$ localized prostate cancer patients with preoperative CTCs declined precipitous after operation $(<24 \mathrm{~h})$, which suggested a short half-life for CTCs in the blood circulation [85]. Here, two debate questions are discussed.

\section{Motility and mobility}

Cancer metastasis has been correlated with genomics, transcriptomics, proteomics, and metabolomics [86-90]. However, the metastatic procedure of CTCs entering the blood circulation through an active course, passive process, or both, remains unclear [91]. In this review, we introduce the terms motility and mobility to describe the different procedures of tumor cell migration. Motile cancer cells move on their own because they have gained 


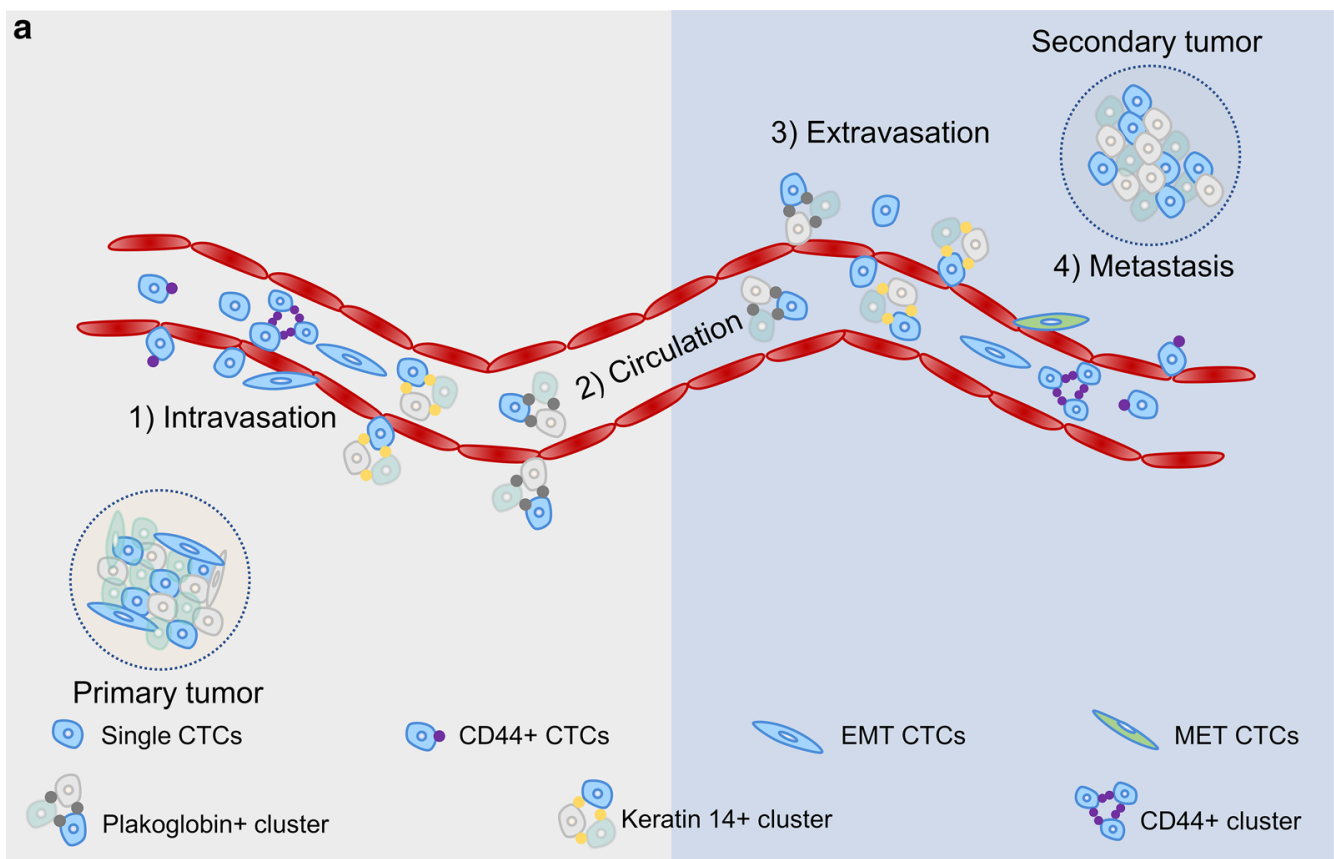

\section{b CTC cluster seeding}

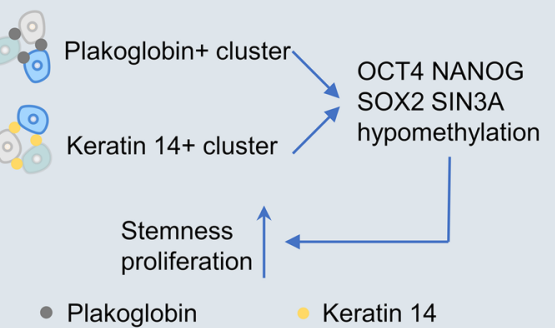

C Intravascular CTC aggregation

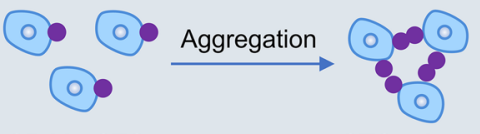

CD44+ CTCs
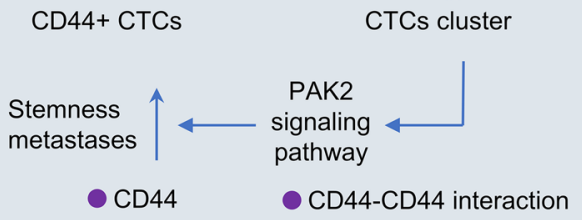

Fig. 4 a Basic metastases process of CTCs and CTCs clusters. b CTC clusters seeding in blood. $\mathbf{c}$ Individual CTCs aggregation in blood

the abilities to seed in the extracellular matrix, undermine basement membranes, and penetrate and evade the vascular wall. The active invasive processes are based on the change of cell morphology, position, and surrounding tissue [92]. Mobile cancer cells are pushed by external forces dragging and pushing them out of place [93, 94]. Two probable mechanisms of passive dissemination of tumor cells are generalized: first, angiogenesis is one of the hallmarks of cancer by secretion of the vascular endothelial growth factor (VEGF), providing nutrients and oxygen for tumor growth. The junctions of neonatal vascular endothelial cells are loose and together with the pushing of tumor during growth result in tumor cell leakage [95]. Second, tumor cells may be passively following the route that was created by other tumor cells through proteolysis [96].

\section{Single cell and CTC cluster}

Epithelial-to-mesenchymal transition (EMT) was debated as a way that initiates metastasis [97]. Alternative hypotheses have been proposed to illustrate the initiation of tumor metastasis from 1976 [98]. By using multiple technological platforms, Aceto and other researchers [99-103] identified 2-50 cancer cell clusters of CTCs from patients with metastatic epithelial cancers (Fig. 4b). Furthermore, in 2014, Aceto et al. [104] first demonstrated that CTC clusters generate from oligoclonal tumor cell groupings rather than from aggregating in the blood vessel. The number of CTC clusters are less than single CTCs, but metastasis is 23-50 times more potent than single CTCs. Aceto et al. [104] certified that plakoglobin-dependent intercellular adhesion promoted CTC clusters originating from connected multicellular groupings, and although less in number, these clusters largely contributed to 
the metastatic spread of cancer. In 2016, Cheung et al. [105] examined how polyclonal metastases form, and demonstrated that cancer cells transferred to distant organs as cohesive clusters composed of two molecularly distinct subpopulations with a variable ratio during metastasis. Moreover, the researchers identified that the mechanism for CTC cluster metastasis is related to keratin $14+(\mathrm{K} 14+)$, which could regulate cell-cell adhesion, cell-matrix adhesion, and immune evasion. In 2019, Aceto and his colleagues [106] further found, based on their previous studies, that the binding sites of transcription factor for stemness and proliferation, including OCT4, NANOG, SOX2, and SIN3A are exactly hypomethylated in CTC clusters, and the biology of CTC clusters are analogous with that of embryonic stem cells. The researchers have confirmed this by profiling the difference of DNA methylation landscape between single CTCs and CTC clusters in breast cancer patients and mouse models on a genome-wide scale. Moreover, they identified $\mathrm{Na}+/ \mathrm{K}+\mathrm{ATPase}$ inhibitors from 2486 FDA-approved compounds to dissociate CTC clusters into single cells. Consequently, DNA methylation of transcription factor was remodeled at critical sites and the metastasis of tumor was suppressed. Finally, Aceto and his colleagues [106] evaluated the therapeutic effect of Ouabain after 3 weeks of treatment. Although the reduction of CTC clusters in mice blood with breast cancer led to a single increase in the number of circulating tumor cells, the total transfer in mice burden was reduced 80.7 times, $98.8 \%$ less than that in the control group, and prevented the formation of new metastases. Furthermore, Aceto pointed out that circulating tumor cell clusters are an important pathway for breast cancer metastasis, and the discovery of the first anti-circulating tumor cell cluster therapy may provide a powerful new tool to help treat millions of women currently living with this potentially fatal disease.

Interestingly, in contrast to Aceto and Cheung, Liu et al. [107] proposed by using intravital multiphoton microscopic imaging that CTC clusters were formed by a single tumor aggregation within the blood vessel rather than from communally migrating cell groups. This finding was confirmed by inoculating cancer cells into veins at different times. Additionally, the researchers revealed that CTC cluster aggregation was attributed to the interactions of homophilic CD44 and subsequent CD44-PAK2 interactions (Fig. 4c).

Further questions emerge from the three different studies. First, two mechanisms of the formation of CTC clusters exist simultaneously; thus, knowing which accounts for a major portion is essential to scientists in developing countermeasures against metastasis.
Moreover, plakoglobin, keratin $14+$, and CD44 are both involved in CTC aggregation, and whether they regulate tumor metastases in a separated or coordinated manner remains a question.

\section{Limitations and outlook}

Although CTCs enable a non-invasive and dynamic analysis of cancer progress, limitations remain. First, CTCs are rare and extremely varied in different types of tumors. Similarly, various CTC detection methods have different boundaries of CTC enumeration to separate patients from the healthy group. To address this issue, the emerging microchip-based devices enable a high isolation efficiency and detection sensitivity of CTCs due to combination of microfluidic-based isolation techniques with nanomaterial-based detection systems into a single automatic platform.

Second, the heterogeneous nature of CTCs and recent research $[28,42]$ show that only certain subgroups of CTCs are capable of metastasis, and current information for detecting and identifying certain subpopulations are limited. Current techniques are already capable of downstream analysis of the released CTCs through culture expansion and single-cell analysis; thus, molecular phenotypes and biological features profiles might assist clinical diagnosis and treatments. In the future, CTC utility can be expanded to monitoring of immune responses of immune checkpoint or vaccination therapies, which can accelerate the translation of CTC research in the upcoming era of cancer immunotherapy.

Finally, CTC-derived 3D organoids are still characterized by limitations, such as lack of immune system, vascularization, and fibroblasts. In addition, these organoids cannot entirely recapitulate interactions at the tissue level in the human body and therefore cannot determine the rate-limiting organ toxicity of drugs [108]. However, microfluidic technology may be able to achieve co-culture of organoids and other cell types, such as immune cells, to imitate in vivo tumor microenvironment [109]. Further exploration is needed on whether CTC-derived organoids capture the complete heterogeneity of the carcinoma.

\section{Conclusion}

CTCs have different physical and biological properties from peripheral blood cells, which can be used to develop new technologies for isolating, identifying, and relieving CTCs in high throughput. As techniques and methods evolve, translating fundamental research into clinical application can be expected. CTCs can be applied in liquid biopsy in early diagnosis, prognosis prediction, disease monitoring, molecular phenotyping, and therapy 
response evaluation. Moreover, metastasis begins with CTCs shedding from the primary tumor into the peripheral circulation. Recently, Klotz et al. [110] have cultured CTCs derived from patients with metastatic luminal breast cancers ex vivo. Intriguingly, a subset of them could adapt and grow in the brain. Therefore, therapies targeting CTCs can potentially reduce metastasis.

Moreover, the CTC-derived 3D organoid model plays a vital role in precision oncology because it can conserve tumor heterogeneity, imitate the cancer microenvironment, and maintain cancer oncogenesis and metastasis. This could gradually replace tissue biopsies which are painful and may be difficult to operate depending on the tumor location. To conclude, CTCs present a new dimension and horizon for clinical doctors in diagnosis, prognosis, prediction, treatment, disease mechanism, and drug development.

\begin{abstract}
Abbreviations
CTCs: circulating tumor cells; cfDNA: cell-free DNA; ctDNA: cell-free tumor DNA; TEPs: tumor-educated blood platelets; CSF: cerebrospinal fluid; FDA: Food and Drug Administration; STn: sialyl-Tn antigen; GFP: green fluorescent protein; TRAIL: tumor necrosis factor-related apoptosis-inducing ligand; AUC : area under the curve; FR+-CTCs: folate receptor positive circulating tumor cells; MTD: maximum tumor diameter; SPNs: solitary pulmonary nodules; AGC: advanced gastric cancer; CDX: CTC-derived explant; ECM: extracellular matrix; CRC: colorectal cancer; PD1: programmed cell death protein 1; PD-L1: programmed death-ligand 1; HER2: human epidermal growth factor receptor 2; CRISPR: clustered regularly interspaced short palindromic repeats; Cas9: CRISPR-associated protein 9; APCKO: adenomatous polyposis coli knock out; TP53KO: tumor suppressor p53 knockout; KRASG12D: the single-nucleotide mutation on codon-12 of exon-2 induces replacement of the GGT sequence (encoding for glycine) by the GAT sequence (aspartic acid-G12D-c35 G4A) of Kirsten rat sarcoma viral proto-oncogene; SMAD4KO: mothers against decapentaplegic homolog 4 knock out; RNF43: ring finger protein 43; ALK: anaplastic lymphoma kinase; CTLA-4: cytotoxic T-lymphocyte-associated protein 4; VEGF: vascular endothelial growth factor; EMT: epithelial-to-mesenchymal transition; K14: keratin 14; OCT4: octamer-binding transcription factor 4; NANOG: homeobox transcription factor Nanog; SOX2: SRY-Box 2; SIN3A: SIN3 transcription regulator family member A; CD44: hematopoietic cell E- and L-selectin ligand; PAK2: P21 activated kinase 2; TGF $\beta 1$ : transforming growth factor beta 1; SNAIL1: zinc finger protein SNAI1; FABP: fatty acid-binding protein; CEACAM5: carcinoembryonic antigen; CD24: cluster of differentiation 24; CD133: prominin-1; ALDH1: aldehyde dehydrogenase 1 family, member A1; RRM1: ribonucleoside-diphosphate reductase large subunit; MAPK14: mitogen-activated protein kinase 14; EGFR: epidermal growth factor receptor; AKT1: AKT serine/threonine kinase 1; AKT2: AKT serine/threonine kinase 2; PIK3R1: phosphatidylinositol 3-kinase regulatory subunit alpha; PTEN: phosphatase and tensin homolog; RAS: Ras GTPase; BRAF: serine/threonine-protein kinase B-Raf; AR: androgen receptor; ER: oestrogen receptor; ERCC1: DNA excision repair protein ERCC-1.
\end{abstract}

\section{Acknowledgements}

We apologize to those colleagues whose important work could not be cited due to space constraints. We thank Ming-Zhu Jin and Ou-Yang Wen for their valuable advice and technical support.

\section{Authors' contributions}

WLJ and GL designed the manuscript, $C Y$ and BRX wrote the manuscript, $C Y$ drew the figures and tables, WLJ mainly revised the manuscript, GL made some revisions of the review. All the authors read and approved the final manuscript.

\section{Funding}

This work was supported by the National Key Research and Development Program of China (No. 2017FYA0205302) and the National Natural Science Foundation of China (No. 81872507 and No. 81872430).

\section{Availability of data and materials}

Not applicable.

\section{Ethics approval and consent to participate}

Not applicable.

\section{Consent for publication}

Not applicable.

\section{Competing interests}

The authors declare that they have no competing interests.

\section{Author details}

1 Department of Gynecology Oncology, The Tumor Hospital, Harbin Medical University, Harbin 150086, People's Republic of China. ${ }^{2}$ Institute of Nano Biomedicine and Engineering, Shanghai Engineering Center for Intelligent Diagnosis and Treatment Instrument, Department of Instrument Science and Engineering, Key Laboratory for Thin Film and Microfabrication Technology of Ministry of Education, School of Electronic Information and Electronic Engineering, Shanghai Jiao Tong University, Shanghai 200240, People's Republic of China. ${ }^{3}$ National Center for Translational Medicine, Collaborative Innovational Center for System Biology, Shanghai Jiao Tong University, Shanghai 200240, People's Republic of China.

Received: 5 October 2019 Accepted: 10 December 2019

Published online: 18 December 2019

\section{References}

1. Siegel RL, Miller KD, Jemal A. Cancer statistics, 2019. CA Cancer J Clin. 2019;69(1):7-34.

2. Key Fact of Cancer. World Health Organization; 2018 https://www.who. int/news-room/fact-sheets/detail/cancer.

3. Menzies AM, Haydu LE, Carlino MS, Azer MW, Carr PJA, Kefford RF, et al. Inter- and intra-patient heterogeneity of response and progression to targeted therapy in metastatic melanoma. PLoS ONE. 2014;9(1):e85004.

4. De Heer EC, Brouwers AH, Boellaard R, Sluiter WJ, Diercks GFH, Hospers GAP, et al. Mapping heterogeneity in glucose uptake in metastatic melanoma using quantitative ${ }^{18} \mathrm{~F}$-FDG PET/CT analysis. EJNMMI Res. 2018;8(1):101.

5. Chua KLM, Yeo ELL, Shihabudeen WA, Tan SH, Shwe TT, Ong EHW, et al. Intra-patient and inter-patient comparisons of DNA damage response biomarkers in Nasopharynx Cancer (NPC): analysis of NCC0901 randomised controlled trial of induction chemotherapy in locally advanced NPC. BMC Cancer. 2018;18:1095.

6. Dutta D, Heo I, Clevers HJ. Disease modeling in stem cell-derived 3D organoid systems. Trends Mol Med. 2017;23(5):393-410.

7. Crowley E, Di Nicolantonio F, Loupakis F, Bardelli A. Liquid biopsy: monitoring cancer-genetics in the blood. Nat Rev Clin Oncol. 2013;10(8):472-84.

8. Corcoran RB, Chabner BA. Application of cell-free DNA analysis to cancer treatment. N Engl J Med. 2018;379(18):1754-65.

9. Comino-Mendez I, Turner N. Predicting relapse with circulating tumor DNA analysis in lung cancer. Cancer Discov. 2017;7(12):1368-70.

10. Chen G, Huang AC, Zhang W, Zhang G, Wu M, Xu W, et al. Exosomal PD-L1 contributes to immunosuppression and is associated with antiPD-1 response. Nature. 2018;560(7718):382-6.

11. Joosse SA, Pantel K. Tumor-educated platelets as liquid biopsy in cancer patients. Cancer Cell. 2015;28(5):552-4.

12. De Mattos-Arruda L, Mayor R, Ng CK, Weigelt B, Martinez-Ricarte F, Torrejon D, et al. Cerebrospinal fluid-derived circulating tumour DNA better represents the genomic alterations of brain tumours than plasma. Nat Commun. 2015;6:8839.

13. Wang Y, Springer S, Mulvey CL, Silliman N, Schaefer J, Sausen M, et al. Detection of somatic mutations and HPV in the saliva and plasma of 
patients with head and neck squamous cell carcinomas. Sci Transl Med. 2015;7(293):293ra104.

14. Kimura H, Fujiwara Y, Sone T, Kunitoh H, Tamura T, Kasahara K, et al. EGFR mutation status in tumour-derived DNA from pleural effusion fluid is a practical basis for predicting the response to gefitinib. Br J Cancer. 2006;95(10):1390-5.

15. Reckamp KL, Melnikova VO, Karlovich C, Sequist LV, Camidge DR, Wakelee $\mathrm{H}$, et al. A highly sensitive and quantitative test platform for detection of NSCLC EGFR mutations in urine and plasma. J Thorac Oncol. 2016;11(10):1690-700.

16. Diehl F, Schmidt K, Durkee KH, Moore KJ, Goodman SN, Shuber AP, et al. Analysis of mutations in DNA isolated from plasma and stool of colorectal cancer patients. Gastroenterology. 2008;135(2):489-98.

17. Zhang Z, Shiratsuchi H, Palanisamy N, Nagrath S, Ramnath N. Expanded circulating tumor cells from a patient with ALK-positive lung cancer present with EML4-ALK rearrangement along with resistance mutation and enable drug sensitivity testing: a case study. JThorac Oncol. 2016:12:397-402.

18. Jordan NV, Bardia A, Wittner BS, Benes C, Ligorio M, Zheng Y, et al. HER2 expression identifies dynamic functional states within circulating breast cancer cells. Nature. 2016;537(7618):102-6.

19. Ashworth TR. A case of cancer in which cells similar to those in the tumours were seen in the blood after death. Aust Med J. 1869;14:146.

20. Giannopoulou L, Kasimir-Bauer S, Lianidou ES. Liquid biopsy in ovarian cancer: recent advances on circulating tumor cells and circulating tumor DNA. Clin Chem Lab Med. 2018;56(2):186-97.

21. Soler A, Cayrefourcq L, Mazard T, Babayan A, Lamy PJ, Assou S, et al. Autologous cell lines from circulating colon cancer cells captured from sequential liquid biopsies as model to study therapy-driven tumor changes. Sci Rep. 2018;8(1):15931.

22. Sefrioui D, Blanchard F, Toure E, Basile P, Beaussire L, Dolfus $C$, et al. Diagnostic value of CA19.9, circulating tumour DNA and circulating tumour cells in patients with solid pancreatic tumours. Br J Cancer. 2017;117(7):1017-25.

23. Poudineh M, Sargent EH, Pantel K, Kelley SO. Profiling circulating tumour cells and other biomarkers of invasive cancers. Nat Biomed Eng. 2018;2(2):72-84

24. Sh S. Silicone flotation: a simple quantitative method for the isolation of free-floating cancer cells from the blood. Cancer Biomark. 1959;12(3):590-5.

25. Nagrath S, Sequist LV, Maheswaran S, Bell DW, Irimia D, Ulkus L, et al. Isolation of rare circulating tumour cells in cancer patients by microchip technology. Nature. 2007;450(7173):1235-9.

26. Alexander RF, Spriggs Al. The differential diagnosis of tumor cells in circulating blood. J Clin Path. 1960;13:414.

27. O'Hara SM, Moreno JG, Zweitzig DR, Gross S, Gomella LG, Terstappen LW. Multigene reverse transcription-PCR profiling of circulating tumor cells in hormone-refractory prostate cancer. Clin Chem. 2004;50(5):826-35.

28. Zhang L, Ridgway LD, Wetzel MD, Ngo J, Yin W, Kumar D, et al. The identification and characterization of breast cancer CTCs competent for brain metastasis. Sci Transl Med. 2013;5(180):180ra48.

29. Racila E, Euhus D, Weiss AJ, Rao C, Mcconnell J, Terstappen LWMM, et al. Detection and characterization of carcinoma cells in the blood. Proc Natl Acad Sci USA. 1998:95:4589-94.

30. Antonarakis ES, Lu C, Wang H, Luber B, Nakazawa M, Roeser JC, et al. AR-V7 and resistance to enzalutamide and abiraterone in prostate cancer. N Engl J Med. 2014;371(11):1028-38.

31. De Rubis G, Rajeev Krishnan S, Bebawy M. Liquid biopsies in cancer diagnosis, monitoring, and prognosis. Trends Pharmacol Sci. 2019;40(3):172-86.

32. Hamza B, Ng SR, Prakadan SM, Delgado FF, Chin CR, King EM, et al. Optofluidic real-time cell sorter for longitudinal CTC studies in mouse models of cancer. Proc Natl Acad Sci USA. 2019;116(6):2232-6.

33. Antfolk M, Magnusson C, Augustsson P, Lilja H, Laurell T. Acoustofluidic, label-free separation and simultaneous concentration of rare tumor cells from white blood cells. Anal Chem. 2015;87(18):9322-8.

34. Abdulla A, Liu W, Gholamipour-Shirazi A, Sun J, Ding X. High-throughput isolation of circulating tumor cells using cascaded inertial focusing microfluidic channel. Anal Chem. 2018;90(7):4397-405.
35. Neves M, Azevedo R, Lima L, Oliveira MI, Peixoto A, Ferreira D, et al. Exploring sialyl-Tn expression in microfluidic-isolated circulating tumour cells: a novel biomarker and an analytical tool for precision oncology applications. N Biotechnol. 2019;49:77-87.

36. Wittekind C, Neid M. Cancer invasion and metastasis. Oncology. 2005;69(Suppl 1):14-6.

37. Kim YR, Yoo JK, Jeong CW, Choi JW. Selective killing of circulating tumor cells prevents metastasis and extends survival. J Hematol Oncol. 2018;11(1):114.

38. Rana K, Liesveld JL, King MR. Delivery of apoptotic signal to rolling cancer cells: a novel biomimetic technique using immobilized TRAIL and E-selectin. Biotechnol Bioeng. 2009;102(6):1692-702.

39. Phipps LE, Hino S, Muschel RJ. Targeting cell spreading: a method of sensitizing metastatic tumor cells to TRAlL-induced apoptosis. Mol Cancer Res. 2011;9(3):249-58.

40. Mitchell MJ, King MR. Fluid shear stress sensitizes cancer cells to receptor-mediated apoptosis via trimeric death receptors. New J Phys. 2013;15:015008.

41. Worrede A, Meucci O, Fatatis A. Limiting tumor seeding as a therapeutic approach for metastatic disease. Pharmacol Ther. 2019:199:117-28.

42. Baccelli I, Schneeweiss A, Riethdorf S, Stenzinger A, Schillert A, Vogel $V$, et al. Identification of a population of blood circulating tumor cells from breast cancer patients that initiates metastasis in a xenograft assay. Nat Biotechnol. 2013;31(6):539-44.

43. Miyamoto DT, Lee RJ, Kalinich M, LiCausi JA, Zheng Y, Chen T, et al. An RNA-based digital circulating tumor cell signature is predictive of drug response and early dissemination in prostate cancer. Cancer Discov. 2018;8(3):288-303.

44. Sparano J, O'Neill A, Alpaugh K, Wolff AC, Northfelt DW, Dang CT, et al. Association of circulating tumor cells with late recurrence of estrogen receptor-positive breast cancer: a secondary analysis of a randomized clinical trial. JAMA Oncol. 2018:4(12):1700-6.

45. Guo W, Sun YF, Shen MN, Ma XL, Wu J, Zhang CY, et al. Circulating tumor cells with stem-like phenotypes for diagnosis, prognosis, and therapeutic response evaluation in hepatocellular carcinoma. Clin Cancer Res. 2018;24(9):2203-13.

46. Zhou Q, Geng Q, Wang L, Huang J, Liao M, Li Y, et al. Value of folate receptor-positive circulating tumour cells in the clinical management of indeterminate lung nodules: a non-invasive biomarker for predicting malignancy and tumour invasiveness. EBioMedicine. 2019;41:236-43.

47. Philips GK, Atkins M. Therapeutic uses of anti-PD-1 and anti-PD-L1 antibodies. Int Immunol. 2015;27(1):39-46.

48. Mazel M, Jacot W, Pantel K, Bartkowiak K, Topart D, Cayrefourcq L, et al. Frequent expression of PD-L1 on circulating breast cancer cells. Mol Oncol. 2015;9(9):1773-82.

49. David R. PD-L1 expression by circulating breast cancer cells. Lancet Oncol. 2015;16(7):e321.

50. Scher HI, Heller G, Molina A, Attard G, Danila DC, Jia X, et al. Circulating tumor cell biomarker panel as an individual-level surrogate for survival in metastatic castration-resistant prostate cancer. J Clin Oncol. 2015;33(12):1348-55.

51. Li Y, Gong J, Zhang Q, Lu Z, Gao J, Li Y, et al. Dynamic monitoring of circulating tumour cells to evaluate therapeutic efficacy in advanced gastric cancer. Br J Cancer. 2016;114(2):138-45.

52. Balakrishnan A, Koppaka D, Anand A, Deb B, Grenci G, Viasnoff V, et al. Circulating tumor cell cluster phenotype allows monitoring response to treatment and predicts survival. Sci Rep. 2019;9(1):7933.

53. Jin $M Z$, Han RR, Qiu GZ, Ju XC, Lou G, Jin WL. Organoids: an intermediate modeling platform in precision oncology. Cancer Lett. 2018:414:174-80

54. Lou YR, Leung AW. Next generation organoids for biomedical research and applications. Biotechnol Adv. 2018;36(1):132-49.

55. Gao D, Vela I, Sboner A, laquinta PJ, Karthaus WR, Gopalan A, et al. Organoid cultures derived from patients with advanced prostate cancer. Cell. 2014;159(1):176-87.

56. Weeber F, van de Wetering M, Hoogstraat M, Dijkstra KK, Krijgsman $\mathrm{O}$, Kuilman T, et al. Preserved genetic diversity in organoids cultured from biopsies of human colorectal cancer metastases. Proc Natl Acad Sci USA. 2015:112(43):13308-11. 
57. Clevers H. Modeling development and disease with organoids. Cell. 2016;165(7):1586-97.

58. Drost J, van Jaarsveld RH, Ponsioen B, Zimberlin C, van Boxtel R, Buijs $A$, et al. Sequential cancer mutations in cultured human intestinal stem cells. Nature. 2015;521(7550):43-7.

59. Sato T, Vries RG, Snippert HJ, van de Wetering M, Barker N, Stange $\mathrm{DE}$, et al. Single Lgr 5 stem cells build crypt-villus structures in vitro without a mesenchymal niche. Nature. 2009;459(7244):262-5.

60. Sato T, Stange DE, Ferrante M, Vries RG, Van Es JH, Van den Brink $\mathrm{S}$, et al. Long-term expansion of epithelial organoids from human colon, adenoma, adenocarcinoma, and Barrett's epithelium. Gastroenterology. 2011;141(5):1762-72.

61. Bissell MJ, Hall HG, Parry G. How does the extracellular matrix direct gene expression? J Theor Biol. 1982;99(1):31-68.

62. Parry G, Cullen B, Kaetzel CS, Kramer R, Moss L. Regulation of differentiation and polarized secretion in mammary epithelial cells maintained in culture: extracellular matrix and membrane polarity influences. J Cell Biol. 1987;105(5):2043-51.

63. Lee GY, Kenny PA, Lee EH, Bissell MJ. Three-dimensional culture models of normal and malignant breast epithelial cells. Nat Methods. 2007:4(4):359-65.

64. Sachs N, de Ligt J, Kopper O, Gogola E, Bounova G, Weeber F, et al. A living biobank of breast cancer organoids captures disease heterogeneity. Cell. 2018;172(1-2):373-86 e10.

65. Huch M, Boj SF, Clevers H. Lgr5(+) liver stem cells, hepatic organoids and regenerative medicine. Regen Med. 2013;8(4):385-7.

66. Karthaus WR, laquinta PJ, Drost J, Gracanin A, van Boxtel R, Wongvipat $J$, et al. Identification of multipotent luminal progenitor cells in human prostate organoid cultures. Cell. 2014;159(1):163-75.

67. Bartfeld S, Clevers H. Organoids as model for infectious diseases: culture of human and murine stomach organoids and microinjection of Helicobacter pylori. J Vis Exp. 2015. https://doi.org/10.3791/53359.

68. Boj SF, Hwang Cl, Baker LA, Chio II, Engle DD, Corbo V, et al. Organoid models of human and mouse ductal pancreatic cancer. Cell. 2015;160(1-2):324-38.

69. Zhang L, Ridgway LD, Wetzel MD, Ngo J, Yin W, Kumar D, et al. The identification and characterization of breast cancer CTCs competent for brain metastasis. Sci Transl Med. 2013;5(180):180ra48-ra48.

70. Zhang Z, Shiratsuchi H, Lin J, Chen G, Reddy RM, Azizi E, et al. Expansion of CTCs from early stage lung cancer patients using a microfluidic co-culture model. Oncotarget. 2014;5(23):12383-97.

71. Fumagalli A, Drost J, Suijkerbuijk SJ, van Boxtel R, de Ligt J, Offerhaus $\mathrm{GJ}$, et al. Genetic dissection of colorectal cancer progression by orthotopic transplantation of engineered cancer organoids. Proc Natl Acad Sci USA. 2017;114(12):E2357-64

72. Hodgkinson CL, Morrow CJ, Li Y, Metcalf RL, Rothwell DG, Trapani F, et al. Tumorigenicity and genetic profiling of circulating tumor cells in small-cell lung cancer. Nat Med. 2014;20(8):897-903.

73. Boehnke K, Iversen PW, Schumacher D, Lallena MJ, Haro R, Amat $J$, et al. Assay establishment and validation of a high-throughput screening platform for three-dimensional patient-derived colon cancer organoid cultures. J Biomol Screen. 2016;21(9):931-41.

74. Nabipour I, Assadi M. Precision medicine, an approach for development of the future medicine technologies. ISMJ. 2016;19:167-84.

75. van de Wetering M, Francies HE, Francis JM, Bounova G, lorio F, Pronk $A$, et al. Prospective derivation of a living organoid biobank of colorectal cancer patients. Cell. 2015;161(4):933-45.

76. Zhang Z, Shiratsuchi H, Palanisamy N, Nagrath S, Ramnath N. Expanded circulating tumor cells from a patient with ALK-positive lung cancer present with EML4-ALK rearrangement along with resistance mutation and enable drug sensitivity testing: a case study. J Thorac Oncol. 2017;12(2):397-402.

77. Dijkstra KK, Cattaneo CM, Weeber F, Chalabi M, van de Haar J, Fanchi LF, et al. Generation of tumor-reactive T cells by co-culture of peripheral blood lymphocytes and tumor organoids. Cell. 2018;174(6):1586-98 e12.

78. Hanahan D, Weinberg RA. Hallmarks of cancer: the next generation. Cell. 2011;144(5):646-74.

79. Allard WJ, Matera J, Miller MC, Repollet M, Connelly MC, Rao C, et al. Tumor cells circulate in the peripheral blood of all major carcinomas but not in healthy subjects or patients with nonmalignant diseases. Clin Cancer Res. 2004;10(20):6897-904.

80. Cristofanilli M, Budd GT, Ellis MJ, Stopeck A, Matera J, Miller MC, et al. Circulating tumor cells, disease progression, and survival in metastatic breast cancer. N Engl J Med. 2004;351 (8):781-91.

81. Cristofanilli M, Hayes DF, Budd GT, Ellis MJ, Stopeck A, Reuben JM, et al. Circulating tumor cells: a novel prognostic factor for newly diagnosed metastatic breast cancer. J Clin Oncol. 2005;23(7):1420-30.

82. Riethdorf S, Fritsche H, Muller V, Rau T, Schindlbeck C, Rack B, et al. Detection of circulating tumor cells in peripheral blood of patients with metastatic breast cancer: a validation study of the cell search system. Clin Cancer Res. 2007;13(3):920-8.

83. Zhang L, Riethdorf S, Wu G, Wang T, Yang K, Peng G, et al. Meta-analysis of the prognostic value of circulating tumor cells in breast cancer. Clin Cancer Res. 2012;18(20):5701-10.

84. Kurihara T, Itoi T, Sofuni A, Itokawa F, Tsuchiya T, Tsuji S, et al. Detection of circulating tumor cells in patients with pancreatic cancer: a preliminary result. J Hepatobiliary Pancreat Surg. 2008;15(2):189-95.

85. Stott SL, Lee RJ, Nagrath S, Yu M, Miyamoto DT, Ulkus L, et al. Isolation and characterization of circulating tumor cells from patients with localized and metastatic prostate cancer. Sci Transl Med. 2010;2(25):25ra3-ra3.

86. Pantel K, Speicher MR. The biology of circulating tumor cells. Oncogene. 2016;35(10):1216-24.

87. Mohme M, Riethdorf S, Pantel K. Circulating and disseminated tumour cells - mechanisms of immune surveillance and escape. Nat Rev Clin Oncol. 2017;14(3):155-67.

88. Millner LM, Linder MW, Roland Valdes J. Circulating tumor cells: a review of present methods and the need to identify heterogeneous phenotypes. Ann Clin Lab Sci. 2013;43(3):2013.

89. Martin OA, Anderson RL, Narayan K, MacManus MP. Does the mobilization of circulating tumour cells during cancer therapy cause metastasis? Nat Rev Clin Oncol. 2017;14(1):32-44.

90. Krishnamurthy N, Spencer E, Torkamani A, Nicholson L. Liquid biopsies for cancer: coming to a patient near you. J Clin Med. 2017;6(1):3.

91. Joosse SA, Pantel K. Biologic challenges in the detection of circulating tumor cells. Cancer Res. 2013;73(1):8-11.

92. Friedl P, Alexander S. Cancer invasion and the microenvironment: plasticity and reciprocity. Cell. 2011;147(5):992-1009.

93. Camara O, Kavallaris A, Nöschel H, Rengsberger M, Jörke C, Pachmann K. Seeding of epithelial cells into circulation during surgery for breast cancer: the fate of malignant and benign mobilized cells. World J Surg Oncol. 2006;4:67.

94. Fornvik D, Andersson I, Dustler M, Ehrnstrom R, Ryden L, Tingberg A, et al. No evidence for shedding of circulating tumor cells to the peripheral venous blood as a result of mammographic breast compression. Breast Cancer Res Treat. 2013;141(2):187-95.

95. McDonald DM, Baluk P. Significance of blood vessel leakiness in cancer. Cancer Res. 2002;62(18):5381-5.

96. Friedl P, Wolf K. Proteolytic interstitial cell migration: a five-step process. Cancer Metastasis Rev. 2009:28(1-2):129-35.

97. Ledford H. Cancer theory faces doubts. Nature. 2011;472(7343):273.

98. Liotta LA, Saidel MG, Kleinerman J. The significance of hematogenous tumor cell clumps in the metastatic process. Cancer Res. 1976;36(3):889-94.

99. Cho EH, Wendel M, Luttgen M, Yoshioka C, Marrinucci D, Lazar D, et al. Characterization of circulating tumor cell aggregates identified in patients with epithelial tumors. Phys Biol. 2012;9(1):016001.

100. Isaiah JF. The relationship of ernbolic homogeneity, number, size and viability to the incidence of experimental metastas. Eur J Cancer. 1973;9:223-7.

101. Molnar B, Ladanyi A, Tanko L, Sreter L, Tulassay Z. Circulating tumor cell clusters in the peripheral blood of colorectal cancer patients. Clin Cancer Res. 2001;7(12):4080-5.

102. Stott SL, Hsu CH, Tsukrov DI, Yu M, Miyamoto DT, Waltman BA, et al. Isolation of circulating tumor cells using a microvortex-generating herringbone-chip. Proc Natl Acad Sci USA. 2010;107(43):18392-7.

103. Yu M, Bardia A, Wittner BS, Stott SL, Smas ME, Ting DT, et al. Circulating breast tumor cells exhibit dynamic changes in epithelial and mesenchymal composition. Science. 2013;339(6119):580-4. 
104. Aceto N, Bardia A, Miyamoto DT, Donaldson MC, Wittner BS, Spencer JA, et al. Circulating tumor cell clusters are oligoclonal precursors of breast cancer metastasis. Cell. 2014;158(5):1110-22.

105. Cheung KJ, Padmanaban V, Silvestri V, Schipper K, Cohen JD, Fairchild AN, et al. Polyclonal breast cancer metastases arise from collective dissemination of keratin 14-expressing tumor cell clusters. Proc Natl Acad Sci USA. 2016;113(7):E854-63.

106. Gkountela S, Castro-Giner F, Szczerba BM, Vetter M, Landin J, Scherrer $R$, et al. Circulating tumor cell clustering shapes DNA methylation to enable metastasis seeding. Cell. 2019;176(1-2):98-112.e14.

107. Liu X, Taftaf R, Kawaguchi M, Chang YF, Chen W, Entenberg D, et al. Homophilic CD44 interactions mediate tumor cell aggregation and polyclonal metastasis in patient-derived breast cancer models. Cancer Discov. 2019;9(1):96-113.

108. Praharaj PP, Bhutiab SK, Nagrath S, Bitting RL, Gagan D. Circulating tumor cell-derived organoids: current challenges and promises in medical research and precision medicine. BBA Rev Cancer. 2018:2018:117-27.

109. Yin X, Mead BE, Safaee H, Langer R, Karp JM, Levy O. Engineering stem cell organoids. Cell Stem Cell. 2016;18(1):25-38.

110. Klotz R, Thomas A, Teng T, Han SM, Iriondo O, Li L, et al. Circulating tumor cells exhibit metastatic tropism and reveal brain metastasis drivers. Cancer Discov. 2019. https://doi.org/10.1158/2159-8290. CD-19-0384.

111. Van der Auwera I, Peeters D, Benoy IH, Elst HJ, Van Laere SJ, Prove $A$, et al. Circulating tumour cell detection: a direct comparison between the Cell Search System, the AdnaTest and CK-19/mammaglobin RT-PCR in patients with metastatic breast cancer. Br J Cancer. 2010;102(2):276-84.

112. Saucedo-Zeni N, Mewes S, Niestroj R, Gasiorowski L, Murawa D, Nowaczyk $\mathrm{P}$, et al. A novel method for the in vivo isolation of circulating tumor cells from peripheral blood of cancer patients using a functionalized and structured medical wire. Int J Oncol. 2012;41(4):1241-50.

113. Gorges TM, Penkalla N, SchalkT, Joosse SA, Riethdorf S, Tucholski J, et al. Enumeration and molecular characterization of tumor cells in lung cancer patients using a novel in vivo device for capturing circulating tumor cells. Clin Cancer Res. 2016;22(9):2197-206.

114. Zhian L, Alberto F, Eva K, Alexander S, Ingeborg T, Nonnenmacher A, et al. Negative enrichment by immunomagnetic nanobeads for unbiased characterization of circulating tumor cells from peripheral blood of cancer patients. J TransI Med. 2011;9:70.

115. Harb W, Fan A, Tran T, Danila DC, Keys D, Schwartz M, et al. Mutational analysis of circulating tumor cells using a novel microfluidic collection device and qPCR assay. Transl Oncol. 2013;6(5):528-38.

116. Chinen LT, de Carvalho FM, Rocha BM, Aguiar CM, Abdallah EA, Campanha D, et al. Cytokeratin-based CTC counting unrelated to clinical follow up. J Thorac Dis. 2013;5(5):593-9.

117. Harouaka RA, Nisic M, Zheng SY. Circulating tumor cell enrichment based on physical properties. J Lab Autom. 2013;18(6):455-68.

118. Wan Y, Winter M, Delalat B, Hardingham JE, Grover PK, Wrin J, et al. Nanostructured polystyrene well plates allow unbiased highthroughput characterization of circulating tumor cells. ACS Appl Mater Interfaces. 2014;6(23):20828-36.

119. Riahi R, Gogoi P, Sepehri S, Zhou Y, Handique K, Godsey J, et al. A novel microchannel-based device to capture and analyze circulating tumor cells (CTCs) of breast cancer. Int J Oncol. 2014;44(6):1870-8.

120. Gascoyne PR, Shim S. Isolation of circulating tumor cells by dielectrophoresis. Cancers (Basel). 2014;6(1):545-79.
121. Waheed W, Alazzam A, Mathew B, Christoforou N, Abu-Nada E. Lateral fluid flow fractionation using dielectrophoresis (LFFF-DEP) for size-independent, label-free isolation of circulating tumor cells. J Chromatogr B Analyt Technol Biomed Life Sci. 2018;1087-1088:133-7.

122. De Luca F, Rotunno G, Salvianti F, Galardi F, Pestrin M, Gabellini S, et al. Mutational analysis of single circulating tumor cells by next generation sequencing in metastatic breast cancer. Oncotarget. 2016;7(18):26107-19.

123. Tulley S, Zhao Q, Dong H, Pearl ML, Chen WT. Vita-assay method of enrichment and identification of circulating cancer cells/circulating tumor cells (CTCs). Methods Mol Biol. 2016;1406:107-19.

124. Alix-Panabieres C. EPISPOT assay: detection of viable DTCs/CTCs in solid tumor patients. Recent Results Cancer Res. 2012;195:69-76.

125. Togo S, Katagiri N, Namba Y, Tulafu M, Nagahama K, Kadoya K, et al. Sensitive detection of viable circulating tumor cells using a novel conditionally telomerase-selective replicating adenovirus in non-small cell lung cancer patients. Oncotarget. 2017;8(21):34884-95.

126. Powell AA, Talasaz AH, Zhang H, Coram MA, Reddy A, Deng G, et al. Single cell profiling of circulating tumor cells: transcriptional heterogeneity and diversity from breast cancer cell lines. PLoS ONE. 2012;7(5):e33788.

127. Giordano A, Gao H, Anfossi S, Cohen E, Mego M, Lee BN, et al. Epithelial-mesenchymal transition and stem cell markers in patients with HER2-positive metastatic breast cancer. Mol Cancer Ther. 2012;11(11):2526-34.

128. Smirnov DA, Zweitzig DR, Foulk BW, Miller MC, Doyle GV, Pienta KJ, et al. Global gene expression profiling of circulating tumor cells. Cancer Res. 2005:65(12):4993-7.

129. Pestrin M, Bessi S, Puglisi F, Minisini AM, Masci G, Battelli N, et al. Final results of a multicenter phase II clinical trial evaluating the activity of single-agent lapatinib in patients with HER2-negative metastatic breast cancer and HER2-positive circulating tumor cells. A proof-of-concept study. Breast Cancer Res Treat. 2012;134(1):283-9.

130. Kalykaki A, Agelaki S, Kallergi G, Xyrafas A, Mavroudis D, Georgoulias V. Elimination of EGFR-expressing circulating tumor cells in patients with metastatic breast cancer treated with gefitinib. Cancer Chemother Pharmacol. 2014;73(4):685-93.

131. Kallergi G, Agelaki S, Kalykaki A, Stournaras C, Mavroudis D, Georgoulias V. Phosphorylated EGFR and PI3K/Akt signaling kinases are expressed in circulating tumor cells of breast cancer patients. Breast Cancer Res. 2008;10(5):R80.

132. Mostert B, Jiang Y, Sieuwerts AM, Wang H, Bolt-de Vries J, Biermann K, et al. KRAS and BRAF mutation status in circulating colorectal tumor cells and their correlation with primary and metastatic tumor tissue. Int J Cancer. 2013:133(1):130-41.

133. Paoletti C, Larios JM, Muñiz MC, Aung K, Cannell EM, Darga EP, et al. Heterogeneous estrogen receptor expression in circulating tumor cells suggests diverse mechanisms of fulvestrant resistance. Mol Oncol. 2016;10(7):1078-85.

134. Kuhlmann JD, Wimberger P, Bankfalvi A, Keller T, Scholer S, Aktas B, et al. ERCC1-positive circulating tumor cells in the blood of ovarian cancer patients as a predictive biomarker for platinum resistance. Clin Chem. 2014;60(10):1282-9

\section{Publisher's Note}

Springer Nature remains neutral with regard to jurisdictional claims in published maps and institutional affiliations. 